This item was submitted to Loughborough's Research Repository by the author.

Items in Figshare are protected by copyright, with all rights reserved, unless otherwise indicated.

\title{
Valuing aircraft noise: stated choice experiments reflecting inter-temporal noise changes from airport relocation
}

PLEASE CITE THE PUBLISHED VERSION

http://www.springerlink.com/content/y64286g016v5k346/

\section{PUBLISHER}

(C) Springer Science+Business Media B.V

\section{VERSION}

AM (Accepted Manuscript)

\section{LICENCE}

CC BY-NC-ND 4.0

\section{REPOSITORY RECORD}

Thanos, Sotirios, Mark Wardman, and Abigail L. Bristow. 2019. "Valuing Aircraft Noise: Stated Choice Experiments Reflecting Inter-temporal Noise Changes from Airport Relocation”. figshare.

https://hdl.handle.net/2134/9239. 
This item was submitted to Loughborough's Institutional Repository (https://dspace.lboro.ac.uk/) by the author and is made available under the following Creative Commons Licence conditions.

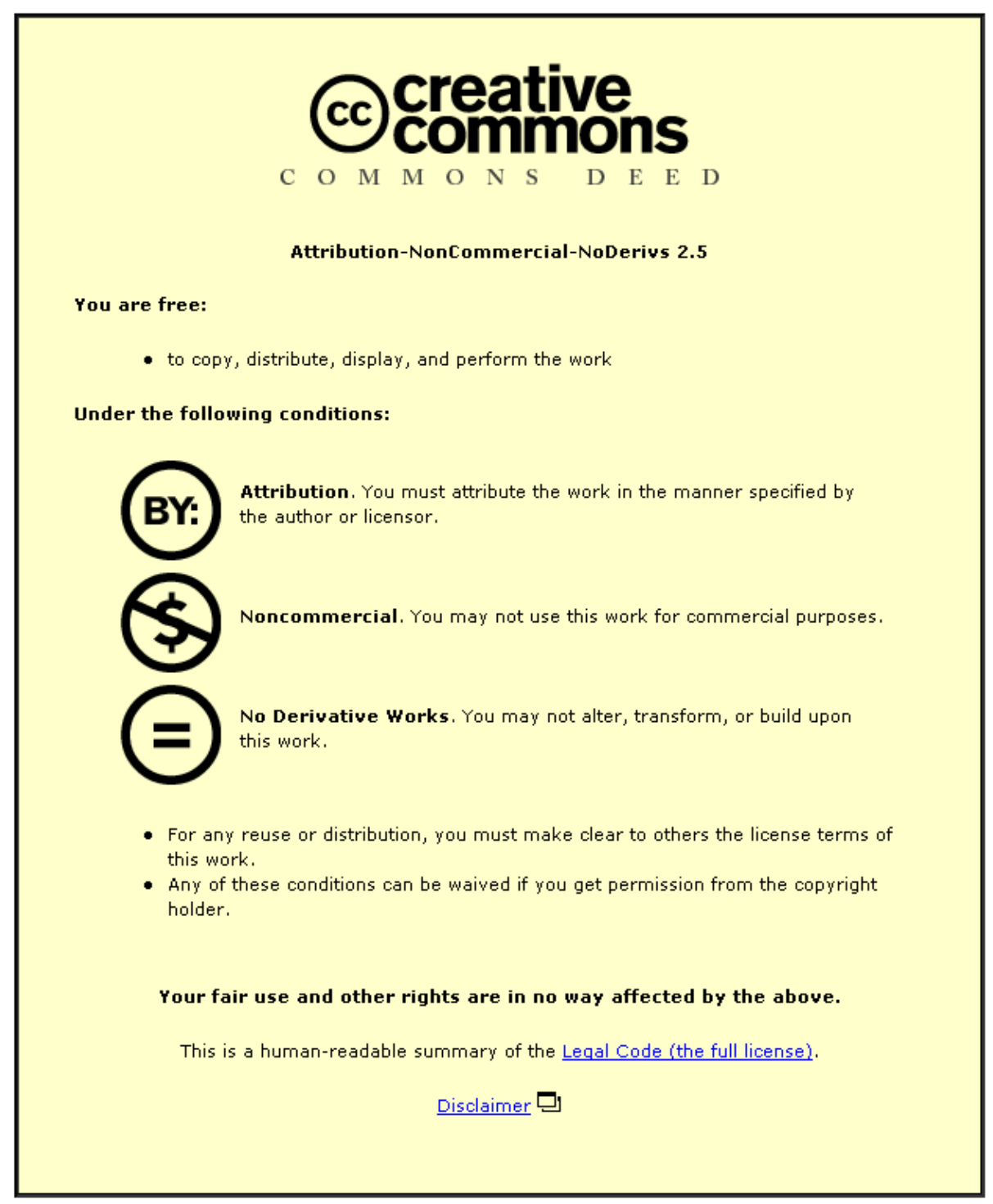

For the full text of this licence, please go to: http://creativecommons.org/licenses/by-nc-nd/2.5/ 


\title{
Valuing aircraft noise: Stated Choice experiments reflecting inter-temporal noise changes from airport relocation
}

\author{
Sotirios Thanos*, Mark Wardman^, Abigail L. Bristow ${ }^{\#}$
}

\begin{abstract}
The relocation of Athens Airport provided a rare experimental context in which residents experienced significant changes in noise levels due to the introduction or removal of aircraft noise. This paper reports the results from surveys around both airport locations, using stated choice experiments to estimate values for aircraft noise. The respondents were offered actual inter-temporal noise change scenarios rather than hypothetical variations, which is uncommon in the literature, incorporating the presence or absence of an airport and other relevant transport attributes that also changed with the airport relocation. Whilst there is some variation in the valuation of the airport closure and opening, when these values are adjusted to reflect the actual change in decibels, there is remarkably little difference between the old and new airports. However, a significant variation in aircraft noise values is identified between different areas, with respect to education and to a lesser extent income. Our preferred estimate of the monthly household willingness to pay for terminating aircraft noise exposure is $13.12 €$ and for avoiding the onset of aircraft noise is $9.53 €$.
\end{abstract}

Keywords: Aircraft Noise, Choice Experiments, Environmental Valuation, Stated Choice, Stated Preference, Willingness to Pay, Willingness to Accept Compensation.

*Corresponding Author, School of Built Environment, Heriot-Watt University, Sir William Arrol Building, EH14 4AS, Edinburgh, UK, e-mail: $\underline{\text { S.Thanos@hw.ac.uk }}$

^Institute for Transport Studies, University of Leeds, Leeds, UK

\#Transport Studies Group, Department of Civil and Building Engineering, Loughborough University, Loughborough, UK 


\section{Introduction}

Noise disturbance is a key externality of the aviation sector. Around 6.9 million people in Europe are exposed to aviation noise levels exceeding $55 \mathrm{dBL}_{\mathrm{den}}$ and the numbers are expected to grow in the absence of further policy intervention (European Environment Agency, 2010). Whilst individual aircraft have become quieter, this has been offset by growth in aircraft movements and the expansion of secondary airports.

Valuation of the costs of aircraft noise annoyance is necessary to inform policy and appraisal. Valuation has traditionally relied upon hedonic pricing techniques to identify the impact of aviation noise on house prices (Nelson, 2004), with the key attraction being its basis in actual behaviour. However, the approach does have limitations, including: the difficulty of measuring intangible influences and how they are perceived; inability to identify key influential factors on noise valuations; high correlation of explanatory variables; market imperfections, such as high transaction costs and imperfect knowledge of the attributes of different houses and locations; and inability to purchase the exact combination of desired attributes. Stated Preference (SP) approaches offer an opportunity to focus on aspects of interest in a controlled experimental setting and can examine current preferences at a disaggregate level.

Contingent Valuation (CV) is a particular form of SP that obtains a response on willingness to pay (or accept compensation) for a particular product or change and has been used for many years in environmental valuation. However, there are only a limited number of studies of aircraft noise (Pommerehne, 1988; Thune-Larsen 1995; Fietelson et al., 1996; Faburel 2001; MVA et al., 2007; Duarte and Cladera, 2008) and these exhibit a wide degree of variation in findings. Stated Choice (SC) techniques, where respondents express a choice amongst two or more hypothetical alternatives characterised by a range of relevant variables, have been widely used in marketing and transport demand forecasting and valuation. This approach has become an accepted tool in the valuation of environmental resources and externalities (Hanley et al., 2001; Wardman and Bristow, 2004; Hoyos, 2010). We are, 
however, aware of only four studies employing SC techniques in the context of aircraft noise (Thune-Larsen, 1995; Carlsson et al., 2004; MVA, 2007; Wardman and Bristow, 2008).

All studies of noise valuation based upon hypothetical questioning methods face three significant challenges. Firstly, a presentational one of realistically conveying changes in aircraft noise to respondents, which can be critical to obtaining reliable data. Secondly, a measurement one of relating perceptions of the presented noise levels to measured or modelled physical noise levels, which is essential for appraisal. Finally, the risk of attracting biased responses given the often controversial nature of aircraft noise.

In terms of presentation, previous studies used hypothetical changes in aircraft noise presented as: changes in the numbers of aircraft (Carlsson et al., 2004; MVA, 2007; Wardman and Bristow 2008); percentage changes in noise levels (Pommerehne, 1988; Thune-Larsen, 1995); categorical changes in noise levels (Wardman and Bristow 2008); and the elimination of annoyance (Faburel, 2001). Clearly, these means of representation may be subject to varying interpretations by respondents. Only the Duarte and Cladera (2008) study used an experienced change in noise, by addressing the recent expansion of Barcelona airport, but their study did not include estimates of actual noise levels. The second and related problem is that of linking perceived changes in aircraft noise through such representations with an objective measure, which is rarely undertaken in SP experiments dealing with noise. The third challenge relates to incentives for bias, and indeed implausibly large valuations of aircraft noise have been obtained when the purpose of the SC exercise to value aircraft noise was transparent (MVA, 2007; Wardman and Bristow, 2008).

Two rare occurrences yielding an irresistible research opportunity were the opening of Eleftherios Venizelos Airport and the closure of Hellenikon Airport in Athens, both occurring in 2001. This resulted in the complete removal of aircraft noise around Hellenikon Airport and the onset of aircraft noise around Eleftherios Venizelos Airport. The relocation of Athens airport offered a unique context in which to study the impacts of aircraft noise. This enables the SC experiment to be based on changes in noise levels that respondents have actually experienced. Aircraft noise 
levels may then be modelled for each respondent's location, providing a decibel value for this change. Hence, respondents' perceptions of noise change are directly linked to a change in decibels. This represents a novel approach to the valuation of aircraft noise addressing two of the challenges raised above. In addition, the incentive to strategic bias may be reduced in this context since one airport has moved and it will not come back. Moreover, to the best of our knowledge this research produced the first monetary valuations of aircraft noise nuisance for Greece.

The structure of this paper is as follows. Section 2 provides details about the context of the airport relocation and expands on this research opportunity and the noise valuation challenges it addresses. Section 3 covers methodological issues such as the SC experimental design and implementation and the noise modelling. Section 4 illustrates the SC modelling approach and its results. Section 5 presents and discusses the monetary aircraft noise valuation estimates and is followed by conclusions in Section 6 .

\section{Background}

\section{$2.1 \quad$ The Airport Relocation Context}

In 2000, around 150,000 people resided in the study areas around Hellenikon Airport. Aircraft noise, from approximately 510 aircraft movements per day, has now ceased. The new Eleftherios Venizelos Airport had a surrounding population of about 53,000 people in 2001, which has almost doubled since then. About 520 movements per day were experienced by the residents in 2006. We are therefore here dealing with significant variations in aircraft noise and related annoyance in each location. Henceforth, we term Hellenikon Airport the "Old Airport" and Eleftherios Venizelos the "New Airport" for clarity.

The announcement of the closure of the Old Airport sparked a debate on the use of the airport land that intensified after its closure. The official plans for the Airport land use were finalised in July 2007, with most of the land being converted into a park. However, this debate was ongoing and the outcome uncertain during the period of this study. 
Given the controversy surrounding the use of the former airport land, we felt it essential to cover this dimension within the SC experiments.

An airport is part of the transport network of a city, and thus its relocation will bring transport changes. Road traffic levels are often affected whilst the opening of the New Airport brought new light rapid transit links to the area. In the Old Airport area a tram system was introduced as part of the preparations for the 2004 Olympic Games. These form natural candidates for inclusion in the SC exercise.

\subsection{The Research Opportunity}

Of the two candidate SP methods for this valuation exercise, SC was favoured over CV since it considers a wide range of attributes simultaneously. This was important in designing an experiment that closely reflects the airport relocation context and to reducing incentives to strategic bias, by masking the purpose of the study as discussed in section 2.2.3. Compared to open-ended CV, SC is more aligned to real-world decision making and less susceptible to protest response (Wardman and Bristow, 2004).

\subsubsection{Presentation}

One of the main challenges facing the valuation of environmental attributes in general and noise in particular, within a SC survey based context, is that of presenting the attribute in question in a realistic and understandable fashion. Noise cannot be sensibly presented in the decibel units in which it is usually measured and hence researchers have had to make use of other methods of presentation.

A simple approach is to use categorical scales, such as 'very noisy', 'noisy', 'quite noisy' and so on (Wardman and Bristow, 2008). The main problem is to relate these scales to actual levels of noise and to be able to know when a change in noise causes an individual to move from one category to another. Offering proportionate changes in noise has been a common approach (Thune-Larsen, 1995; Sælinsminde, 1999; Wardman and Bristow, 2004). Two key 
drawbacks are respondents' difficulties in understanding percentage changes and appreciating the actual noise change that the percentage change would imply. Respondents can experience the environmental impact under experimental 'laboratory controlled' conditions (Garrod et al., 2002). However, noise simulation is a very expensive approach whilst respondents may be affected by the artificial and usually limited exposure. A proxy measure, such as hypothetical changes in aircraft movements, can be used to imply variations in aircraft noise. Noise measures are then estimated for the different movements (Bristow and Wardman, 2006a; Le Masurier et al., 2008). This method relies on respondents being able to relate to the noise levels that would exist under different numbers of movements and does not relate to respondents' actual experience of different noise levels.

An attractive approach is to ask respondents to compare different locations, usually homes, with different noise levels. This requires that there are no confounding effects, such as differences in house quality, and that respondents are familiar with the noise differences. Although such conditions can be identified and exploited (Arsenio et al., 2006; Dave et al., 2009), they are not common. Pommerehne (1988) offered the identical residence elsewhere with a lower noise exposure level, but this is essentially the same as the proportionate change method.

Finally, the noise variation might take on a temporal dimension, where at the same location there are differences in noise levels over time, such as by time of day, week or year. Despite the attractions of such a method, based as it is on individuals' experiences of different and measurable noise levels, we are only aware of two such applications both of which used CV experiments (Barreiro et al., 2005; Duarte and Cladera, 2008). On a larger scale, intertemporal noise variation might be based on the closure of an existing airport and/or the opening of a new one. We are not aware of the application of such an attractive approach underpinning SC noise valuation and here we exploit this novel opportunity.

\subsubsection{Estimation of physical noise levels}


Physical noise level estimates are required for both the presence and absence of an airport in the stated choice experiments. In the case of the presence of an airport, modelled noise data based on actual aircraft movements are available. In the case of the absence of an airport, reasonable assumptions are made about background noise levels in order to estimate the noise level changes from the airport relocation. The modelled noise levels represent experienced rather than hypothetical changes in noise levels which avoids the problem faced in attempting to link a hypothetical change to a physical change. The process is detailed in section 3.3.

\subsubsection{Incentives to bias}

In addition to the presentational and noise estimation challenges that we seek to address here, we also aim to minimise the incentives to various forms of response bias. Airport expansion and aircraft noise are emotive issues, and thus it would be naïve not to expect strategic and/or protest bias to be at least a potential problem in this context. Indeed, aircraft noise emerged as a very real problem for local residents after the New Airport became operational and this provides them with an incentive for protest response.

The residents around the Old Airport ought not to have a strong incentive to influence policy decisions or to protest, since the airport has already been relocated. The residents around the New Airport similarly cannot influence the policy of whether the airport is there, and hence there will be less incentive to strategic bias than if the SC exercise had been offered prior to opening. Whilst there remains an incentive to protest against the airports existence and to influence policy regarding future increases in aircraft movements, this was minimised by the interviewers explicitly instructing the respondents to focus on changes they experienced in the past and not to consider future changes.

SP methods can suffer from what is termed hypothetical bias, whereby the unreliability of responses lacking salient economic commitment is exacerbated by scenarios or changes that seem implausible or incredible (Murphy et al., 2005; Bateman et al., 2002). However, the noise changes presented in the SC experiments were experienced in real life by the vast majority of respondents, which not only contributes to realism but means that they are by definition 
credible because they actually occurred. We stress again that the interviewers and the SC scenarios explicitly instructed the respondents to focus on changes they experienced in the past and not to consider future changes.

An SC exercise that simply offered a trade-off between some measure of aircraft noise and a numeraire term of cost runs the risk of obtaining less reliable noise valuations. The transparency of the study purpose would give respondents a greater incentive to provide responses biased towards influencing policy or to completely reject choice scenarios as a form of protest. By masking the purpose of the study, we might expect a reduced incentive to both strategic and protest bias (Wardman and Bristow, 2008). This airport relocation context, given its association with a range of other changes as outlined above, provides a basis for masking the main purpose of the exercise within a broader quality of life dimension. This is expected to reduce the strategic and protest bias incentives in comparison with more 'naïve' SC and CV applications.

We are confident that the approach adopted minimises response bias and promotes realism. Therefore, more reliable responses are elicited by our approach than by presenting the respondents with arbitrary hypothetical future noise changes that have not been experienced, as is the case for most SC and CV noise studies.

\section{Methodology}

\subsection{Survey Design}

The aircraft noise variable, of critical interest in this study, is defined by the context. The other essential variable relates to money, and the municipal tax was used as the only realistic financial instrument. In order to mask the purpose of the survey, which was presented as an investigation into broader transport-related quality of life issues, a range of other attributes were offered and the noise related section of the questionnaire followed the SC exercise. The additional attributes were public transport travel times to the centre of Athens during the peak period, area wide road traffic levels, and whether there was a light rapid transit stop in the New Airport area or a tram stop in the Old 
Airport area within walking distance. The two experiments with these attributes in the Old and New Airport areas are denoted the OLD5 and NEW experiments respectively.

The pilot surveys confirmed our impressions that the use to which the Old Airport land would be put was indeed a controversial subject. The strength of feeling on this issue warranted the creation of two different experiments for the Old Airport, in the event it dominated responses. Hence, a variant to the OLD5 experiment was created, termed OLD6, that includes an attribute specifying the use to which the Old Airport land would be put.

The SC exercise offered choices between two unlabelled alternatives. An orthogonal fractional factorial design in differences was used. Appendix A illustrates the selected levels of difference for each attribute and the most general design, OLD6, which is identical to the other two designs except for the extra land use variable. The OLD5, OLD6 and NEW designs each contained 25 choice scenarios of which a randomly selected 8 were presented on cards in face-to-face home interviews. An example of the card presentation is given in Appendix B. Pre-tests and a pilot survey were used to inform and assess the design process. A simulation exercise confirmed that the SC design was satisfactory in terms of its ability to recover precise estimates for a range of pre-specified coefficients used to create the synthetic data.

In the experimental design, shown in Appendix A, option B is either the noisier option or the same as option A. The design had three levels of difference for the aircraft noise attribute, although two of these levels were zero to distinguish between both options having the airport and both options not having the airport. The reason for this was to avoid placing too much emphasis on the airport, which might have been a danger had option A always represented the absence of the airport and option B always represented its presence. The same principle was used in the case of whether there was a tram or LRT stop nearby ${ }^{1}$ and with the use of the Old Airport land as a park or not, with again option A tending to be better than option B. However, for the presentation in the survey, option B is renamed option 
A and vice versa in 12 of the 25 choice cards. Thus respondents did not get the impression that either A or B tended to be better, but had to read each card carefully to select the preferred choice.

The design of the OLD6 experiment was slightly modified to avoid presenting scenarios in which the respondent was subjected to aircraft noise and at the same time a park was created on the airport land. Area wide traffic level change was specified as a percentage change from current traffic levels, and public transport peak travel times to the city centre specified as minutes difference from the current level. Both these attributes took five levels of difference each in the experimental design with option A tending to be an improvement on the current situation and option B tending to be a deterioration.

The tax paid to the local municipality was used as a payment vehicle. This "municipal tax" is included in the utility bill (water and electricity) for households. Pre-tests, focus groups and the pilot survey showed that even though all residents were aware of the "municipal tax", most could not specify the exact amount paid because of its inclusion in utility bills, even though the overall amount of the utility bill was known by most residents. Hence, a range of increases and reductions to the municipal tax can be offered, without being perceived implausible, although introducing municipal tax changes of over $60 €$ per month was regarded to be unrealistic by most pilot survey respondents. The municipal tax was offered as €s per month, since people are more familiar with monthly payments.

Five levels of tax difference of $10 €, 20 €, 35 €, 50 €$ and $60 €$ per month were offered. Given that the other attributes tend to be better for option A, and therefore to ensure trade-offs were offered, option B was preferable on cost grounds. Option A incurred an increase on the currently paid tax and option B was the same or less. As stated above, in terms of presentation to respondents A and B were mixed such that A was not always better. 


\subsection{Survey Implementation}

The selected study areas are those municipalities and townships most directly affected by the airports. There is, however, much variation of aircraft noise exposure within these municipalities. The study areas for the Old Airport were the municipalities of Glyfada, Hellenikon, Alimos and Palaio Faliro and for the New Airport the townships of Koropi, Markopoulo and Artemis. The sampling frame included the adult population of these areas.

The main survey took place between October and December 2005. The survey was based on random geographical coverage of the study areas with cluster sampling within specified areas for practicality. Interviewers were provided with maps, each of a randomly selected geographical area of about 3 to 4 street blocks, where she/he visited all houses door to door. Almost all the interviews took place during the evenings and weekends to avoid biasing the sample towards those who are at home during the day. $34 \%$ of those approached agreed to be interviewed. Each interview was conducted by the researcher face-to-face in the respondent's home. The analysis is based on 700 returned questionnaires, after removing 11 that were insufficiently complete and providing a dataset of 5600 SC observations. Of these, 1608 (28.7\%) were for OLD5, 2136 (38.1\%) for OLD6 and 1856 (33.1\%) for NEW experiment.

We tested our data sample for socioeconomic inconsistencies in categories that can be problematic in survey data, often over-representing categories of people who tend to be at home during the day, such as females, people not in full employment and elderly individuals. Statistical tests were employed to compare firstly the socioeconomic consistency between Old and New Airports sub-samples and secondly the combined Old/New-Airport data with the wider Athens area. When comparing the Old to the New Airport data sub-sample, we cannot reject at the $1 \%$ level the null hypothesis of the differences being zero between percentages of people in full employment (z-score: 2.3), over 65 (z-score: 0.39) and females (z-score: 1.14). This demonstrates the consistency between the two subsamples. 
Unfortunately, most of the relevant official data in Greece are only available at the level of prefecture, which is too large for precise comparisons. Hence, we cannot place too much emphasis on comparisons with data lacking sufficient detail and can only illustrate a broad consistency of our sample with the population in the wider Athens area (National Statistical Service of Greece, 2005). To that effect, we cannot reject at the $1 \%$ level that $45.3 \%$ of females in our sample is statistically different to $49.3 \%$ in the population of the wider area (z-score: 1.96$)$. The over 65 category was $15.9 \%$ in our data, which is not statistically different to $16.1 \%$ of people over 65 in the wider Athens area (z-score: -0.08). We were not able to obtain employment data for Athens prefecture in 2005, so we compare our sample with the whole of Greece. The difference between the $54.7 \%$ in full employment in our sample and $53.3 \%$ of full-time employment for Greece in 2005 is not statistically significant (z-score: 0.74$)$. The average income levels for the municipalities around the Old Airport are higher than the Greek average, ranging from around $15000 €$ to more than $26000 €$. This seems to be broadly in agreement with our data, in which the average household income falls into the $18-24000 €$ category $^{2}$. The only issue was the $21.4 \%$ of respondents who did not state their income band.

\subsection{Incorporating Aircraft Noise Exposure}

The physical aircraft noise estimates were supplied by the European Organisation for the Safety of Air Navigation (EUROCONTROL), who have complete data on flight paths and aircraft movements for both airports. Radar data were employed to derive more accurate aircraft approaches to the airport and the Integrated Noise Model (Federal Aviation Administration, 2003) was employed for the aircraft noise modelling. The consistency of the modelled data with actual noise measurements was confirmed by EUROCONTROL. A set of coordinates for each interviewee's address was provided to EUROCONTROL and they supplied an estimate of the aircraft noise exposure for the specific coordinates. The aircraft noise estimates for the New Airport corresponded to a month before the survey took place (15/09/2005-15/10/2005). For the Old Airport, the noise estimates correspond to the same month in 2000 $(15 / 09 / 2000-15 / 10 / 2000)$, the last year of its operation. 
Appropriate and available noise indices included: $L_{\text {eq }}$ the equivalent continuous sound pressure level over a fixed time period; $\mathrm{L}_{\mathrm{den}}$ a 24 hour $\mathrm{L}_{\text {eq }}$ measure, where the evening values (18:00 - 22:00) are weighted by the addition of 5 $\mathrm{dBA}$ (A-weighted decibel), and the night values (22:00 - 06:00) are weighted by the addition of $10 \mathrm{dBA}$ and $\mathrm{L}_{\max }$ which is the maximum sound pressure level from a single event. The $\mathrm{L}_{\mathrm{den}}$ noise metric (here measured over a 30 day period) is seen as appropriate for aircraft noise in the EU (EC, 2002) and here it produces better fitting SC models than $\mathrm{L}_{\mathrm{eq}}$ and $\mathrm{L}_{\max }$.

Table 1 presents average aircraft noise exposure data for the different survey areas. There is much variation in aircraft noise exposure across the various municipalities of the study area. Residents around the Old Airport and especially those in Alimos were exposed to by far the highest noise levels. Yang and Kang (2005) concur on the very high noise levels in Alimos. Artemis residents have the highest aircraft noise exposure of the areas around the New Airport.

Table 1: Aircraft noise levels in dBA $\left(L_{d e n}\right)$ by area

\begin{tabular}{lcr|lrr}
\hline New Airport Areas & Mean & Stdev & Old Airport Areas & Mean & Stdev \\
\hline Artemis & 56.5 & 4.0 & Glyfada-Hellenikon & 63.4 & 4.6 \\
Koropi-Markopoulo & 48.3 & 4.9 & Alimos & 69.5 & 3.9 \\
& & & Palaio Faliro & 66.5 & 3.5 \\
\hline
\end{tabular}

The 'no-aircraft noise' situation in the SC experiments clearly does not relate to a zero decibel level since there would be 'background' noise pollution from traffic and from other sources. From previous studies of the noise situation in Athens (Nicol and Wilson, 2004; Yang and Kang, 2005), it can be deduced that a 55dBA value for background noise would be a reasonable approximation for the area around the Old Airport. Location categories in the literature (Attenborough and Clark, 1976; Baverstock et al., 1991; Alberola et al., 2005) that resemble the characteristics of the New Airport study area have background noise levels between 47 and $49 \mathrm{dBA}$. Hence, $47 \mathrm{dBA}$ is taken as the background noise level before the operation of the New Airport. 
The aircraft noise level $\left(\Gamma_{a}\right)$ and the assumed background noise level $\left(\Gamma_{b}\right)$ are combined in a total noise level $\left(\Gamma_{t}\right)$ that is given by:

$$
\Gamma_{t}\left(\Gamma_{a}, \Gamma_{b}\right)=10 L O G_{10}\left(10^{\frac{\Gamma_{a}}{10}}+10^{\frac{\Gamma_{b}}{10}}\right)
$$

The $\Gamma_{t}$ represents the presence of aircraft noise in the SC experiment. The absence of aircraft noise is simply the background noise level $\Gamma_{b}$. If $\Gamma_{a}$ is dominant, $\Gamma_{b}$ will have an almost negligible effect on the total noise level and vice $\operatorname{versa}\left(\Gamma_{a} \oplus \Gamma_{b} \approx \Gamma_{a}\right.$ if $\left.\Gamma_{a} \gg \Gamma_{b}\right)$.

This analysis can be considered a step forward from studies that simply examine variations in aircraft noise above a pre-specified cut off point. Table 2 shows the difference between the total noise level $\left(\Gamma_{t}\right)$ and the background noise level $\left(\Gamma_{b}\right)$ in the different municipalities/townships of our study areas. As expected, the Koropi-Markopoulo areas have the smallest difference from the background levels and Alimos the largest difference. The differences for other areas are broadly similar, implying the operation of an airport introduces about $10 \mathrm{dBA}$ of "extra" noise.

Table 2: The difference between the total noise level $\Gamma_{a}$ and background noise level $\Gamma_{b}$ across the study areas

\begin{tabular}{lrr|lrr} 
New Airport Areas & Mean & Stdev & Old Airport Areas & Mean & Stdev \\
\hline Artemis & $10.2 \mathrm{dBA}$ & 2.8 & Glyfada-Hellenikon & $9.2 \mathrm{dBA}$ & 4.1 \\
Koropi-Markopoulo & $4.3 \mathrm{dBA}$ & 2.5 & Alimos & $14.7 \mathrm{dBA}$ & 3.6 \\
& & & Palaio Faliro & $11.9 \mathrm{dBA}$ & 3.2 \\
\hline
\end{tabular}

\section{Modelling and Results}

\subsection{Model Specification}

By far the most common method used to explain discrete or categorical SC data is the multinomial logit (MNL) model. It relates the probability of a utility maximising individual i choosing option $1\left(P_{i 1}\right)$ from amongst the $\mathrm{n}$ options available as a function of the observable utility $(V)$ associated with each option: 


$$
P_{i 1}=\frac{e^{\theta V_{i 1}}}{\sum_{j=1}^{n} e^{\theta V_{i j}}}
$$

In turn, the utility for any option $j$ is a function of $k$ explanatory variables $(X)$ which might be continuous, such as tax, measured noise levels or travel time, or discrete, such as whether there is a tram stop nearby or a park is created on the airport land. $\theta$ in equation 2 denotes that the coefficient estimates in observable utility $(V)$ functions (equations 3 and 4) are scaled in inverse proportion to the standard deviation of the random component of utility of each option. A conventional linear-additive utility function that here serves as the reference case is:

$$
V_{i j}=\sum_{k=1}^{K} \mu_{k} X_{i j k}+\varphi \psi_{i j}
$$

The coefficient $\mu$ represents the fixed effect of variable $X$. The purpose of $\varphi \psi_{i j}$ is to account for the repeat choices per person in SC data. The term $\psi_{i j}$ is a normally distributed random variable with a mean of zero and a standard deviation of 1. It is distributed independently across alternatives and respondents, but not across observations from the same respondent. The multiplication by the coefficient $\varphi$ allows for the individual-specific effect $\psi$ to be shared across alternatives (Hess, 2008). This specification is employed in the base Models I and II and is further developed for our preferred models.

The computation of all the models in this paper requires Mixed Multinomial Logit (MMNL) models that use simulated maximum likelihood, here based on 1000 Halton draws (Hensher and Greene, 2003) in BIOGEME 1.8 (Bierlaire, 2003).

The reference case utility function of equation 3 is enhanced to distinguish systematic and random taste variation:

$$
V_{i j}=\sum_{k=1}^{K}\left(\mu_{k}+\tau_{k} \xi_{i j}+\sum_{l=1}^{l-1} \beta_{l k} d_{i j l}+\alpha_{k} S\right) X_{i j k}
$$

As above, the coefficient $\mu$ represents the fixed effect of variable $X$. $\xi$ denotes the standard deviation of the effect that 
represents random taste variation across individuals according to some pre-specified distribution, multiplied by the coefficient $\tau$. Similarly to $\varphi \psi_{i j}$ in equation $3, \tau_{k} \xi_{i j}$ accounts for the repeated observations per respondent issue, as $\xi$ is not distributed independently across observations from the same individual.

In addition, we can specify taste variation that is systematically related to observable factors. If we hypothesise that the sensitivity to variable $X$ might be influenced by the $l$ levels of some socio-economic variable, such as age group, we can specify $l-1$ dummy variables $\left(d_{l}\right)$ and the coefficients $\left(\beta_{l}\right)$ denote the incremental effect relative to the arbitrarily omitted category. Thus the sensitivity to $X$ is $\mu$ for the base category and $\mu+\beta_{3}$ for those in the third socioeconomic category. A variation on this is to specify a continuous interaction between some socio-economic variable $S$ and the explanatory variable $X$. The particular form explored here is the effect of income on the sensitivity to tax variations, where we expect those with higher household incomes $(Y)$ to be less sensitive. This takes the form:

$$
\alpha \frac{1}{Y_{i}^{\lambda}} \operatorname{Tax}_{j}
$$

The marginal utility of money for individual $i$ is $a / Y^{\lambda}$ and $\lambda$ is the elasticity of any monetary valuation with respect to income and is directly estimated.

We will have expectations as to the sign of the coefficient estimates but, since the coefficients are estimated in units of residual variation, denoted by $\theta$, their absolute magnitudes have no meaning. This scaling does not impact on the monetary values which are derived as ratios since it applies equally to all coefficients. However, when estimating a model that pools data across, say, different SC exercises, as we have done here, it is essential to allow for possible scale differences across the data sets, otherwise scale variation due to random error can be erroneously attributed to a coefficient estimate. The data is pooled across the OLD5, OLD6 and NEW experiment data sets and allowance is made for scale differences of OLD6 and NEW $\left(\theta_{O L D 6}, \theta_{N E W},\right)$ with the OLD5 experiment serving as the base. 
Four models are reported in Table 3. Models I and II include only the main effects of the SC experiments and differ only in terms of representing aircraft noise simply as a dummy variable relating to the presence of an airport or modelled noise levels. Models III and IV additionally allow for systematic taste variation, according to socioeconomic and attitudinal factors, and random taste variation.

The traffic and tram/LRT coefficients were allowed to vary between the New and the Old Airports due to the differences in transport features between these two areas. The aircraft noise coefficients, at least for the dummy variable specification, can also be expected to vary across airports. Additionally, memory might play a role in the Old Airport valuations whilst the incentive to bias responses is greater for New Airport respondents. Analysis showed somewhat different attitudes towards cost in the OLD6 experiment and thus the cost coefficients were allowed to vary for OLD6 throughout.

It is not common practice to specify an alternative specific constant (ASC) where, as here, choices are made between unlabelled alternatives. Unlike real-world choice contexts, there are no other extraneous influences which might influence choice. Hensher et al. (2005) argue that the correct way to proceed would be to exclude constant terms for all unlabelled alternatives. Hoyos (2010), in a review of the state of the art of environmental valuation with discrete choice experiments, finds that the latest trend in the literature is to use ASCs only for the status quo alternative of unlabeled experiments. Our experiments do not contain a status quo alternative. Whilst it is possible that framing effects can exist in SC experiments, they would not be present in our experiments. As explained in section 3.1, alternative B is renamed alternative A and vice versa in 12 of the 25 choice cards. This directly addresses the framing effect, with respondents not selecting on the basis that either A or B tended to be better but having to read each card carefully to select the preferred choice. Hence, the ASCs cannot possibly capture framing effects in our SC experiments and there is no other theoretical reason for inserting them. 


\begin{tabular}{|c|c|c|c|c|c|c|c|c|}
\hline \multirow[b]{2}{*}{ Fixed Effects $(\mu)$} & \multicolumn{2}{|c|}{$\begin{array}{c}\mathrm{I} \\
\text { (Descriptive } \\
\text { Noise) } \\
\end{array}$} & \multicolumn{2}{|c|}{$\begin{array}{c}\text { II } \\
\text { (Modelled } \\
\text { Noise, dBA) } \\
\end{array}$} & \multicolumn{2}{|c|}{$\begin{array}{c}\text { III } \\
\text { (Descriptive } \\
\text { Noise) } \\
\end{array}$} & \multicolumn{2}{|c|}{$\begin{array}{c}\text { IV } \\
\text { (Modelled } \\
\text { Noise, dBA) }\end{array}$} \\
\hline & Coef & t-stat & Coef $t$ & t-stat & Coef & t-stat & Coef & t-stat \\
\hline Aircraft Noise Exposure(OLD5) & 0.4310 & 2.6 & -0.0210 & 1.5 & 1.1600 & 4.1 & -0.1370 & 3.6 \\
\hline Aircraft Noise Exposure $(N E W)$ & 1.1600 & 5.4 & -0.1300 & 5.1 & 1.5700 & 6.1 & -0.1320 & 5.5 \\
\hline Aircraft Noise Exposure(OLD6) & 0.3810 & 1.4 & -0.0148 & 0.8 & 0.7110 & 2.7 & -0.0551 & 2.6 \\
\hline Traffic Levels (OLD5, OLD6) & -0.0829 & 5.7 & -0.0853 & 5.9 & -0.1040 & 6.8 & -0.1060 & 6.9 \\
\hline Traffic Levels $(N E W)$ & -0.1600 & 8.1 & -0.1710 & 8.6 & -0.2480 & 9.9 & -0.2460 & 10.0 \\
\hline Tram Hellenikon & 0.6340 & 4.5 & 0.6540 & 4.6 & 0.5990 & 3.9 & 0.6200 & 4.1 \\
\hline Light Rail (LR) $(N E W)$ & 1.6300 & 6.4 & 1.7200 & 6.6 & 1.6500 & 6.9 & 1.6400 & 6.9 \\
\hline Use of Airport Land (OLDC) & 2.1000 & 4.4 & 2.1000 & 4.6 & 0.9680 & 2.3 & 0.9890 & 2.3 \\
\hline PT Travel Time (all 3) & -0.0602 & 5.3 & -0.0639 & 5.7 & -0.0715 & 5.5 & -0.0721 & 5.5 \\
\hline Tax increase $(O L D 5, N E W)$ & -0.1250 & 15.1 & -0.1250 & 15.1 & & & & \\
\hline Tax reduction $(O L D 5, N E W)$ & -0.0241 & 3.0 & -0.0235 & 2.9 & & & & \\
\hline Tax increase (OLD6) & -0.1340 & 6.4 & -0.1330 & 6.9 & -0.1900 & 8.4 & -0.1910 & 8.5 \\
\hline Tax reduction (OLD6) & -0.0865 & 4.6 & -0.0857 & 4.8 & -0.0514 & 2.7 & -0.0525 & 2.6 \\
\hline Random Parameters $(\varphi, \tau)$ & Coef & t-stat & Coef $t$ & t-stat & Coef & t-stat & Coef & t-stat \\
\hline$\varphi$ & 2.2100 & 11.3 & 2.2300 & 11.2 & & & & \\
\hline$\tau_{1}:$ Tax increase $(O L D 6)$ & & & & & 0.0923 & 6.2 & 0.0915 & 6.1 \\
\hline$\tau_{2}:$ Tax reduction $(O L D 6)$ & & & & & 0.0674 & 2.1 & 0.0669 & 1.9 \\
\hline$\tau_{3}:$ Aircraft Noise $(O L D 6)$ & & & & & 1.3600 & 3.2 & 0.0902 & 2.6 \\
\hline $\boldsymbol{\tau}_{\mathbf{4}}:$ Light Rail $(N E W)$ & & & & & 2.1200 & 6.7 & 2.1000 & 6.6 \\
\hline$\tau_{5}:$ Traffic Levels (OLD5, OLD6) & & & & & 0.0965 & 5.3 & 0.0932 & 4.9 \\
\hline$\tau_{6}:$ PT Travel Time (all 3) & & & & & 0.1670 & 10.7 & 0.1710 & 10.7 \\
\hline Scale $(\theta)$ & Coef & t-stat & Coef $t$ & t-stat & Coef & t-stat & Coef & t-stat \\
\hline $\boldsymbol{\theta}_{\mathrm{NEW}}$ & 0.3940 & 17.6 & 0.3900 & 17.7 & 0.8050 & 2.7 & 0.8090 & 2.7 \\
\hline $\boldsymbol{\theta}_{\text {OLD6 }}$ & 0.4220 & 7.7 & 0.4270 & 8.0 & 0.6590 & 4.0 & 0.6430 & 4.3 \\
\hline \multicolumn{5}{|c|}{ Continuous Socioeconomic Interactions $(\alpha, \lambda)$} & Coef & t-stat & Coef & t-stat \\
\hline \multicolumn{5}{|c|}{$\boldsymbol{\alpha}_{1}:$ Tax increase $/$ Income $^{\lambda}(O L D 5, N E W)$} & -0.4780 & 3.6 & -0.5020 & 3.6 \\
\hline \multicolumn{5}{|c|}{$\boldsymbol{\alpha}_{2}:$ Tax reduction/Income $\mathbf{e}^{\lambda}(O L D 5, N E W)$} & -0.0767 & 2.1 & -0.0820 & 2.1 \\
\hline \multicolumn{5}{|l|}{$\lambda:$ Income Elasticity } & 0.1860 & 5.1 & 0.1940 & 5.3 \\
\hline \multicolumn{9}{|l|}{ Systematic Incremental Effects $(\beta)$} \\
\hline \multicolumn{5}{|l|}{ Aircraft noise for Alimos (OLD5) } & -0.8600 & 2.5 & 0.1210 & 3.1 \\
\hline \multicolumn{5}{|c|}{ Aircraft noise for Palaio Faliro (OLD5) } & -0.5140 & 1.5 & 0.0771 & 1.9 \\
\hline \multicolumn{5}{|c|}{ Aircraft noise for Koropi-Markopoulo ( $N E W)$} & -1.5600 & 4.8 & 0.1500 & 2.8 \\
\hline \multicolumn{5}{|c|}{ Aircraft noise Education less than 10 years (all 3) } & -0.7970 & 3.3 & 0.0624 & 2.6 \\
\hline \multicolumn{5}{|c|}{ Aircraft noise disliked Airport closure (OLD5, OLD6) } & -1.1300 & 3.2 & 0.1050 & 3.2 \\
\hline \multicolumn{5}{|c|}{ Tram and Light Rail for University Education (OLD5, OLD6) } & 0.4390 & 1.7 & 0.4480 & 1.8 \\
\hline \multicolumn{5}{|c|}{ Land Use of the Old Airport for Glyfada-Hellenikon (OLD6) } & 2.0900 & 4.2 & 2.1100 & 4.2 \\
\hline \multicolumn{5}{|c|}{ Traffic Levels for Artemis Area $(N E W)$} & 0.1160 & 4.7 & 0.1060 & 4.5 \\
\hline \multicolumn{5}{|c|}{ Traffic Levels for those who are not annoyed by noise $(N E W)$} & 0.0653 & 3.0 & 0.0654 & 3.0 \\
\hline Final Likelihood & \multicolumn{2}{|c|}{-3042.37} & \multicolumn{2}{|c|}{-3046.96} & \multicolumn{2}{|c|}{-2607.65} & \multicolumn{2}{|c|}{-2612.98} \\
\hline $\boldsymbol{\rho}^{2}$ (with respect to constants) & \multicolumn{2}{|c|}{0.212} & 0.211 & & 0.3 & & 0.3 & \\
\hline
\end{tabular}

Note: $\mathrm{t}$ ratios for $\theta_{\mathrm{NEW}}$ and $\theta_{\mathrm{OLD} 6}$ are specified with respect to unity 
ASCs were found to be statistically significant, but the preferred models with ASCs were not statistically superior to those without. Our view is that the ASCs have no theoretical justification and their statistical significance is due to correlations with other variables some of whose effects they are appropriating. For example, when inserting ASC in "Model I", we can reject the null hypothesis of its independence from twelve out of the fourteen model parameters at the 5\% level, with the coefficient of four correlations between the ASC and other parameter estimates exceeding 0.3. When there is correlation between the ASC and other terms and a genuine ASC effect is expected to exist, constraining the ASC to zero would be problematic. However, in this case there is no genuine ASC effect, rather a statistical artefact on the choice data. Hence ASCs are not contained in the reported models.

\subsection{The Main Effects Models}

The overall goodness of fit of Models I and II is satisfactory as a value of $\rho^{2}$ between 0.2 and 0.4 is taken as an indication of good overall model fit (Louviere et al., 2000). All coefficients are of the expected sign and most are statistically significant. As would be expected, but with the obvious exception of the aircraft noise coefficients, there is not a great deal of difference in the coefficients across the two models.

Tram and LRT produce very different willingness to pay (WTP) outcomes of around $5 €$ per month and $13 €$ per month respectively, where the numeraire is the tax increase coefficient for OLD5 and NEW experiments. This is attributed to the difference between these transport modes and the poor performance of tram in its first year of operation. Traffic also produces different results for the Old and the New Airports. It was expected that New Airport respondents would perceive increases in traffic levels in the SC experiment as more annoying than Old Airport respondents given their recent experience of increasing traffic. A $10 \%$ reduction in traffic levels would be worth almost $13 €$ per month for New Airport respondents with around half that value in the Old Airport. A minute saving in peak public transport travel times to the centre would be worth $0.48 €$ per month. Whilst the latter would be low as a value of time for a regular public transport commuter to the centre, it must be borne in mind that these would be a minority in the sample and the value reflects an average. The Old Airport land use variable is only applicable for the 
OLD6 Experiment. The significance of this issue is reflected in a WTP of $15.7 €$ per month for turning the airport land to a park.

The aircraft noise coefficient was also allowed to vary across the OLD5, OLD6 and NEW experiments. For the dummy variable specification, we observe them to be quite similar in both experiments for the Old Airport, although for OLD6 it is not significant. The coefficient for the New Airport experiment is somewhat higher. This is also the case when noise measures replace the dummy variables, although then only the New Airport experiment coefficient is significant. These variations could be because New Airport respondents have experienced an increase in noise and Old Airport respondents have experienced a reduction and hence protest response might influence the New Airport valuation. However, the aircraft noise coefficients also capture locational and behavioural variations, such as noise tolerant respondents and those for whom Old Airport operation was directly beneficial. Models III and IV are introduced specifically to address these often opposing effects that are not captured by Models I and II. We subsequently observe more similar figures across New and Old Airports, but with variation between areas.

The New Airport experiment noise coefficients produce reasonable WTP values of 9.28€ per household per month in Model I and 1.04€ per dBA per month in Model II. The corresponding Old Airport values are 3.44€ and 0.17€, although the latter is not significant.

To put the aircraft annoyance valuations into a broader quality of life perspective, Model I implies that the removal of the Old Airport is equivalent to around a 5\% reduction in traffic levels, approximately 7 minutes of reduced public transport time and is valued at two thirds of the presence of a tram stop nearby. The introduction of the New Airport corresponds to around a 7\% increase in traffic levels, a 19 minute increase in public transport times and to $70 \%$ of not having a LRT stop nearby. The presence or not of aircraft noise can therefore be regarded as important in the context of local quality of life. 
The respondents show significantly less sensitivity, by a factor of five, to tax reductions than to tax increases for OLD5 and NEW, although the OLD6 tax coefficient for reductions is much larger despite a broadly similar coefficient for tax increases. Such patterns are common in the literature. Horowitz and McConnell (2002), reviewing 45 studies, found amongst other things a willingness to accept (WTA) to WTP ratio of 10.41 for public non-market goods.

There is an issue here of whether the tax increase coefficients are subject to protest response whilst the tax reduction coefficient might be too low since the survey interviewers reported that some respondents found a tax reduction to be implausible. Wardman and Bristow (2008) also found such a divergence in the context of aircraft noise valuation, but in that case the tax reduction coefficient was not significant, and this was attributed to tax reductions being regarded as unlikely by respondents. Given these observations, considerable empirical evidence supports the use of WTP over WTA. Biased aircraft noise valuation responses could be expected to manifest themselves in the aircraft noise coefficients rather than the cost coefficients. We here have a preference for valuations based on the cost increase coefficients.

\section{3. $\quad$ Systematic and Random Taste Variation}

We have tested for differential sensitivities to the main SC variables that are systematically related to respondents' particular characteristics, such as income, education level, location and attitudes to noise. Models III and IV contain the random and systematic effects significant at least at the $10 \%$ level in one or other of the models. These models represent significant improvements in fit on the corresponding Models I and II.

The scale coefficients in Models I and II $\left(\theta_{N E W}, \theta_{O L D 6}\right)$ indicate these two sets of data contain more error than the OLD5 base. This could indicate that the consideration of the airport land may have introduced an element of bias into OLD6 responses and the NEW experiment responses might contain protest bias, due to the noise experienced. In Models III and IV we note that incremental and random effects tend to be stronger for NEW and OLD6 thereby 
reducing the amount of error associated with these experiments. Hence, the modelling of systematic and random variation has successfully captured effects that would otherwise be in the error term, resulting in a greater similarity in the scale coefficients.

\subsubsection{Systematic Taste Variation}

It was not possible to discern a significant income effect for those who responded to the OLD6 design and this was attributed to these respondents being willing to pay to have a park nearby regardless of their income level. The income elasticity for the remaining respondents, whilst highly significant in Models III and IV, is itself only around 0.2. This may be compared with estimates of cross sectional income elasticities from a small number of other SC studies of transport noise valuations ranging from 0.4 to 0.7 (Wardman and Bristow, 2004; Arsenio et al., 2006; Bristow et al., 2009) and from CV studies of 0.4 to 0.8 (Pommerehne, 1988; Vainio, 2001; Bjørner, 2004). This is in line with evidence in the field of environmental valuation that income elasticities lie between zero and one (Pearce, 1980; Kristrom and Riera, 1996; Hökby and Söderqvist, 2003; Jacobsen and Hanley, 2009) whilst evidence from travel demand analysis research supports a figure of around 0.5 (Wardman, 2001). Although our results correspond with those obtained elsewhere, in indicating that values increase with income but less than proportionately, they are at the lower end of the evidence scale.

There were five significant effects on aircraft noise, three of which are location related. The area effects are important given the different characteristics and levels of exposure of each municipality. Relative to the base category of Glyfada-Hellenikon, it was found that there is less sensitivity to noise in Palaio Faliro and Alimos which were exposed to higher levels of aircraft noise. There may be an element of self-selectivity at work here, in that those living nearer to the airport were people less concerned with aircraft noise. Artemis is the base category in the New Airport experiment, and is the area that is most exposed to aircraft noise. Here we observe that the incremental effects for Koropi-Markopoulo, which is exposed to very low levels of aircraft noise, would imply no WTP and WTA for exposure to aircraft noise in either model. 
This raises the issue of thresholds, and indeed non-linearities, in noise valuations. Whilst in principle these could have been explored here, to determine whether, say, there is some threshold level of noise or noise change below which the valuation is essentially zero, in practice the approximations involved in constructing the noise measures could not support a more detailed analysis.

Those with less than 10 years in full time education were found to be somewhat less sensitive to aircraft noise. Whilst it might be argued that this could stem from this group having more difficulty with SC exercises, we would then have expected more widespread effects. As expected, those who felt that the airport closure was a negative event were even less sensitive to the absence of the airport. People with higher education are willing to pay $73 \%$ more in NEW and 27\% more in OLD5 experiment than the base category to have a LRT or tram stop respectively within walking distance from their house.

The residents of Glyfada-Hellenikon, who live adjacent to the former airport land, were very sensitive to the Airport land use. This is underlined by having a $215 \%$ higher valuation for creating a park compared to residents of Palaio Faliro and Alimos.

Artemis residents were around half as sensitive to changes in traffic levels as residents in the other areas around the New Airport. This is to be expected since Artemis has the lowest levels of traffic. There was a significant incremental effect in that respondents who are not annoyed by noise pollution also have $26 \%$ lower values for road traffic reduction than the base category in NEW experiment. It is conceivable that these people regard both noise and road traffic as a part of city life.

\subsubsection{Random Taste Variation}

Every SC main effect variable was tested for preference heterogeneity and statistically significant random 
parameters were retained. The random parameters follow a normal distribution since we have found no advantage in the use of any alternative distribution.

Three random parameters are exclusive to OLD6. We observe that the spread of the tax increase, tax reduction and aircraft noise parameters would be considerable, to such an extent that the proportion with unexpected signs for tax increases, reductions and aircraft noise would be 2\%, 22\% and 30\% respectively in Model III. In Model IV, the aircraft noise coefficient would have positive sign for $27 \%$ of respondents. However, no significant random variations in aircraft noise or tax were apparent for OLD5 and NEW. We therefore feel that the results specific to OLD6 are attributable to the controversial land use variable that introduced strong feelings into the choice context. Some respondents were prepared to pay any amount to secure the park, presumably caused by strategic response bias, resulting in a sensitivity to cost that was low or indeed had an unexpected sign. This could also explain the absence of an income effect $(\lambda)$ and the very large spread in the aircraft noise coefficient. These results justify our approach of having a separate SC which did not include the controversial land use variable. Given these issues, OLD6 coefficients are not employed in the estimation of aircraft noise monetary values presented below ${ }^{3}$.

There were only three other significant random effects, none of which relate to the tax or aircraft noise terms. These were for LRT, traffic levels at the Old Airport and PT travel time. The preference heterogeneity would imply coefficients of the opposite sign to the mean for $22 \%, 14 \%$ and $33 \%$ respectively. Whilst there are no readily apparent reasons for this pattern of preference, we stress that these variables are not the focus of this research.

\section{Aircraft Noise Monetary Values}

Of primary importance here are the monetary valuations of aircraft noise, reported first for the absolute change (Model III) and then per decibel (Model IV). The WTP and WTA for aircraft noise given by: 


$$
W T P(W T A)_{a i r}=\frac{\mu_{a i r}}{\alpha} \times \mathrm{Y}^{\lambda}
$$

Where $\mu_{\text {air }}$ is a coefficient for aircraft noise, $\alpha$ is the coefficient for $\operatorname{cost}(\operatorname{tax}), \lambda$ is the income elasticity calculated in our models and $Y$ is the average income. The variance and the asymptotic t-statistic of WTP/WTA values in Tables 4 and 5 are estimated using the delta method adapted to equation 6 from the specification of Hole (2007) and Bevington (1969). Tables 4 and 5 contain only those monetary values that are statistically significant at the $10 \%$ level. The last column shows for each category the monthly income used in calculating the respective monetary value.

\subsection{Monetary Values of the Presence or Absence of an Airport}

The monetary valuations of aircraft noise for the absolute change (Model III) are reported in Table 4. As with models I and II, we also see here considerable divergence between the WTP and WTA estimates. We report the latter for completeness but note that we have previously pointed out the reasons for preferring the WTP over the WTA values.

Table 4: Monetary estimates for no-aircraft-noise from Model III

\begin{tabular}{lrr|rr|r}
\hline & $\begin{array}{r}\text { WTP } \\
€ / \text { hh/month }\end{array}$ & t-stat & $\begin{array}{r}\text { WTA } \\
€ / \text { hh/month }\end{array}$ & $\begin{array}{r}\text { t-stat } \\
\text { income }(€)\end{array}$ \\
\hline Base Category & & & & & \\
NEW: Artemis & 13.12 & 2.45 & 81.77 & 1.78 & 1714 \\
OLD5: Glyfada-Hellenikon & 9.53 & 2.23 & 59.43 & 1.68 & 1567 \\
Values after adjusting for Incremental Effects & & & & \\
NEW: Education less than 10 years & 6.00 & 2.48 & 37.36 & 1.80 & 1147 \\
OLD5: Alimos & 2.56 & 2.25 & 15.94 & 1.70 & 1907 \\
OLD5: Palaio Faliro & 5.69 & 2.45 & 35.48 & 1.78 & 2279 \\
OLD5: Education less than 10 years & 2.84 & 2.03 & 17.67 & 1.60 & 1191 \\
\hline
\end{tabular}

The monetary values for the whole effect in Table 4 are higher for the NEW experiment compared to OLD5, even though the aircraft noise exposure is higher in OLD5. This can, in part, be attributed to the noise difference values in Table 2, where not being exposed to aircraft noise in the NEW base category (Artemis) implies a 10.2 dBA reduction 
while in the OLD5 base category it implies a 9.2 dBA reduction. Differences in incentives between the Old and the New Airports concerning strategic and protest bias might also be a factor and/or memory issues for the Old Airport respondents.

There are different starting points concerning aircraft noise exposure ${ }^{4}$ and the changes offered in the experiments, hence the utility levels associated with each point are different. In the NEW experiment people are willing to pay 13.12€/month for terminating their aircraft noise exposure whereas the OLD5 WTP of $9.53 € /$ month is for avoiding the onset of aircraft noise. Income differences between areas would only account for a small amount of the valuation difference. The respondents of the OLD5 experiment would be willing to accept compensation of 59.43€/Month for aircraft noise returning (loss of quietness) in their area. The NEW experiment exhibits a WTA of $81.77 € /$ month for respondents to forgo a change from aircraft noise to "quietness".

Koropi-Markopoulo respondents were exposed to low aircraft noise levels which results in very low aircraft noise monetary values (i.e. a WTP of $0.8 € /$ month) that were not statistically significant at the $10 \%$ level. This implies a threshold of about 48-49dBA at which there is no significant WTP or WTA for aircraft noise. This is consistent with the exposure and annoyance relationship for the New Airport in Thanos (2008, pp: 137) that shows slight noise annoyance commencing after exposure to aircraft noise exceeds $46 \mathrm{dBA}$.

Palaio Faliro and Alimos on the other hand were exposed to higher aircraft noise levels than the base category, but the respondents in these areas exhibit much lower aircraft noise monetary values. This is attributed to noise tolerance and is discussed in the next section. Social or dose response and CV aircraft noise valuation studies have found that noise annoyance is affected by educational level (Garcia et al. 1993, Miedema and Vos 1999; Faburel, 2001). In our data, and independent of any income effect, people with a lower education level have lower monetary values for aircraft noise, which is consistent with the literature. 
An additional group was specified to control for a minority of respondents for whom the closure of the Old Airport was a negative event. Such a preference may offset any benefits in terms of reduced aircraft noise annoyance. Whilst perceiving the closure to be a negative event is a significant incremental effect, the resulting monetary values are not statistically significant. The WTP for this group in the OLD5 experiment is close to zero $(0.25 € /$ month $)$, indicating an offsetting effect as anticipated.

\section{2. $\quad$ Monetary Valuations of Aircraft Noise in decibels}

Table 5 presents WTP and WTA values per decibel from OLD5 and NEW experiments derived from Model IV. The base values for the New and the Old Airport are very similar in this table.

Table 5: WTP and WTA per dBA from Model IV

\begin{tabular}{lrr|rr}
\hline & $\begin{array}{r}\text { WTP } \\
€ / \text { hh/month }\end{array}$ & $\begin{array}{r}\text { WTA } \\
\text { t-stat }\end{array}$ & \\
\hline Base Category & & & & \\
NEW: Artemis (Base Category) & 1.11 & 2.37 & 6.82 & 1.77 \\
OLD5: Glyfada-Hellenikon (Base Category) & 1.14 & 2.14 & 6.96 & 1.66 \\
Values after adjusting for Incremental Effects & & & & \\
NEW: Education less than 10 years & 0.54 & 2.63 & 3.33 & 1.86 \\
OLD5: Alimos & 0.14 & 2.55 & 0.84 & 1.83 \\
OLD5: Palaio Faliro & 0.53 & 2.52 & 3.27 & 1.82 \\
OLD5: Education less than 10 years & 0.59 & 2.62 & 3.59 & 1.86 \\
\hline
\end{tabular}

The values in Table 4 (Model III) that value the absence or presence of an airport may be adjusted to a per dBA value by dividing by the noise differences in Table 2 . The resulting WTP values are $1.29 €$ and $1.04 €$ per dBA per household per month for the NEW and OLD5 experiments respectively. These are reasonably close to the Model IV values in Table 5. The noticeable difference is the considerably higher WTP (and WTA) estimates of the NEW compared to the OLD5 in Model III, which is not the case in Model IV results. This implies that the introduction of modelled noise data in Model IV captures some variation that is lost in the dummy variable specification of Model III. The similar values may suggest that the survey design has been successful in reducing response bias incentives. 
The importance of controlling for systematic taste variation is illustrated by the Palaio Faliro and Alimos effects. Yang and Kang (2005) found Alimos to have the noisiest residential neighbourhoods in their study of 14 urban open areas. Charalampakis (1980) also shows that Alimos was exposed to higher levels of aircraft noise than the neighbouring areas. However, the Palaio Faliro and Alimos noise values are relatively low despite high levels of noise exposure. We attribute this "peculiarity" to noise tolerance that decreases monetary values for aircraft noise by a factor of 8 in the extreme case of Alimos and a factor of 2 in the case of Palaio Faliro. Noise tolerance could have been developed by the prolonged exposure to very high aircraft noise levels since before 1980, as Charalampakis (1980) shows.

This suggests that at high noise levels there may be non-linearities in the response to noise as the willingness to pay is lower than in quieter areas. Unfortunately, the modelled aircraft noise data estimates could not be expected to do justice to detailed analysis of threshold effects, given that we needed to make assumptions about the background noise levels.

\subsection{Comparison of Monetary Valuations of Aircraft Noise and Policy Implications}

There is not a great deal of empirical evidence against which the values obtained here can be compared, partly because there are few studies and partly because in only a very few cases have SC experiments been supported by estimates of physical noise. For aircraft noise, Bristow and Wardman (2006b) is one of the few studies that computed value estimates supported by modelled noise data. Their monthly value range is $3.9-15.1 € / \mathrm{dBA} / \mathrm{hh}$ and 7.9-14.9€/dBA/hh for Manchester and Lyon respectively. A small number of road noise valuation experiments were also supported by noise measurements. Arsenio et al (2006) estimated monthly values for Lisbon between 6.2 and $8.9 € / \mathrm{dBA} / \mathrm{hh}$ and the mean estimate of Galileo and Ortuzar (2005) for Santiago was $4.5 € / \mathrm{dBA} / \mathrm{hh}^{5}$. Even though detailed comparisons are not straightforward, our values are on the lower end of the above SC estimates. This might be due to the effective treatment of bias incentives in our approach, stemming from the credibility and realism of 
offering scenarios of changes that had already been experienced. There is also a lack of evidence on the evolution of values over time and possible issues of cultural variation, further limiting any robust comparisons.

All the aircraft noise values in the literature derived from hedonic pricing (HP) studies are estimated through first stage hedonic models; hence these estimates are market specific and not appropriate for comparison with our estimates. Day et al (2007) successfully produced transferable noise value estimates in a theoretically consistent second stage hedonic model, but only for road and rail noise. Lacking a better comparison, we compare their monetary estimates for road noise with our aircraft noise values. We select their values corresponding to the noise baselines of $57 \mathrm{dBA}$ and $63 \mathrm{dBA}$ that are closest to the noise levels of our base category areas, Artemis and GlyfadaHellenikon (as shown in Table 1), giving monthly values of $2.2 € / \mathrm{dBA}^{5}$ and $3.2 € / \mathrm{dBA}^{5}$ respectively. In both cases our preferred WTP values are lower at $1.11 € / \mathrm{dBA}$ and $1.14 € / \mathrm{dBA}$. We should bear in mind that the Artemis value is for terminating aircraft noise exposure and the Glyfada-Hellenikon is for avoiding the onset of aircraft noise, whereas the Day et al (2007) values are marginal pseudo-Marshallian measures for road noise. Nevertheless, it is noted that our WTP estimates are closer to HP values for road noise than the aircraft noise estimates of other SC studies. As expected, our WTA estimates are much higher than the Day et al (2007) values and much closer to other SC estimates.

Many EU countries adopt a constant unit value per dBA in appraisals usually derived from first-stage hedonic price estimates. However, in a few cases the evidence has supported the use of unit values that increase with the level of noise reflecting the overall housing market response to different levels of noise exposure (Nellthorp et al, 2007). This is also a finding in some CVM and SC studies (Bristow, 2010). This study, in common with other SC studies, explores the noise monetary values of those actually exposed to it and does not find the per unit value necessarily increasing with noise levels. Instead, area effects are identified that suggest an element of self-selection. Whilst this is an uncommon finding, there is other evidence in the literature on road traffic noise valuations to suggest that this is not unreasonable. Baranzini and Ramirez (2005) in an HP study of Geneva find that price changes per decibel are far 
higher in non-urban areas where the background noise is lower than in urban areas. Arsenio et al. (2006) in a SC study of Lisbon find that respondents living on the quiet side of a building have higher marginal values of quiet than those living on the noisier side. This self selectivity effect might reasonably explain why our values are lower than those found by Day et al. (2007).

This interesting finding with respect to self selection in very noisy areas may have some future policy implications. Technological improvements in reducing noise pollution from individual aircraft, regulation and policy intervention have limited the cases of extreme noise exposure, such as Alimos. However, the growth in aircraft movements and the expansion of secondary airports may still lead to an increase in the number of cases of moderate noise pollution, such as Artemis in the New Airport Experiment. Therefore, it may be more appropriate for policy to focus on the latter case that is becoming increasingly important for the welfare of a not insignificant section of the population.

The aircraft noise monetary values from our models would be ideal for use in appraisal, especially for Athens where values would not need to be adjusted for socioeconomic characteristics. The monetised aircraft noise cost could be aggregated across the affected population and inserted in an appraisal framework, such as Cost Benefit Analysis, where it could be compared with the other costs and benefits of a project. If we were to take the population around the Old Airport in 2001 (National Statistical Service of Greece, 2005) and aggregate using the WTP values in Tables 4 and 5, we find that they would be willing to pay $482,600 €$ per month to avoid aircraft noise completely. They would also pay 51,733€ per month to avoid one decibel of aircraft noise. Figures for the New Airport are more difficult to compute due to the lack of official data on the recent changes in population. Nevertheless, such estimates can be useful in estimating the costs and benefits of noise mitigation measures. 


\section{Conclusions}

SC techniques have not been widely used in the context of aircraft noise valuation and this research provides fresh empirical evidence where very little exists. Indeed, it presents the first such evidence for Greece. This paper reports the innovative application of an SC experiment, offering respondents actual inter-temporal noise change scenarios rather than the more common approach of hypothetical variations.

Considering the three significant challenges to experimental research in the context of aircraft noise valuation posed in the introduction, we can conclude that this research has risen to meet these challenges. Firstly the presentational challenge, of realistically conveying changes in aircraft noise to respondents. This research context arose from the closure of the old Hellenikon Airport and its replacement by the new Eleftherios Venizelos Airport, allowing the presentation to the respondents of trade-offs between the presence or not of aircraft noise. The main advantage of real-world inter-temporal change scenarios, compared to the typical approach of offering hypothetical variations, is that the change in aircraft noise has been experienced, and hence it does not need to be presented.

The second challenge is that of measurement and relating perceptions of the presented noise levels to physical noise estimates. This is fully addressed here because firstly the changes in aircraft noise levels have been experienced by respondents and secondly they have been accurately modelled in terms of decibels. Moreover, background noise levels have been incorporated into the "with and without airport" noise levels.

The third challenge was to seek to minimise incentives to bias. Whilst the monetary value for the whole effect of introducing of aircraft noise around New Airport was higher than for the removal of aircraft noise around the Old Airport, this was not the case when the valuations were expressed per decibel. This is attributed to the introduction of aircraft noise capturing variation that is not discerned in the dummy variable specification. We contend that setting the valuation exercise within a broader quality of life dimension contributed to the close similarity of values, when 
one might expect a greater incentive for protest and strategic bias amongst the New Airport sample. In any event, the incentive to strategic bias is here lessened given that the relocation has occurred and hypothetical bias is avoided since the choice context is based on an actual change.

The findings suggest a monthly household WTP of $1.11 €$ to $1.14 €$ per decibel. The willingness to accept compensation range is between $6.82 €$ and $6.96 €$ per decibel. These figures seem reasonable but are lying on the lower end of values in the limited amount of comparable empirical evidence. We may attribute this to successfully addressing the three experimental challenges above. The variation between WTP and WTA is common in the literature and WTA values here should be treated with caution for a number of reasons. Our preference is for the WTP values.

An income elasticity of about 0.2 was recovered, which is consistent with but on the low side of estimates in the literature. It would be extremely informative to conduct repeat studies to determine how valuations vary over time. This is important for appraisal purposes. Other incremental effects on aircraft noise monetary values were the educational level, whether the Airport closure was considered to be a negative change and area effects. In our experience, it is not uncommon that only a very limited number of socio-economic and attitudinal variables impact on the valuation of environmental factors and this is also found to be the case here. The inclusion of the controversial Airport Land use variable introduced high variance and preference heterogeneity in the OLD6 SC experiment that failed to produce reliable monetary value estimates.

Noise tolerance is proposed as an explanation of the "Alimos effect". Alimos was the noisiest area around the Old Airport and was exposed to the highest aircraft noise levels. However, the "per decibel" monetary values for aircraft noise in Alimos are much lower than those of other respondents. Palaio Faliro has similar but lesser traits. One implication of this is that increases in aircraft noise exposure, especially above $66.5 \mathrm{dBA} \mathrm{L} \mathrm{L}_{\mathrm{den}}$, do not necessarily mean increases in noise values; the opposite may be true. At the other end of aircraft noise exposure, the Koropi- 
Markopoulo results imply a threshold of about $48-49 \mathrm{dBA}$ at which there is no significant WTP or WTA for aircraft noise. Whilst this study has covered a large range of noise variations, a detailed analysis of threshold effects and non-linearities would require much more precise data on aircraft and background noise than was available to us. We strongly recommend further research into issues of functional form.

\section{Acknowledgements}

We would like to thank EUROCONTROL Experimental Centre for funding this research and especially Ted Elliff and Ian Fuller for their considerable help. The content of the paper and any opinions expressed are the sole responsibility of the authors. 
Table A1: Attributes and attribute levels ${ }^{\mathrm{a}}$

\begin{tabular}{|c|c|c|c|c|c|c|c|c|c|c|c|}
\hline \multicolumn{2}{|c|}{$\begin{array}{l}\text { Aircraft Noise } \\
(1=\text { no noise }, \\
0=\text { noise })\end{array}$} & \multicolumn{2}{|c|}{$\begin{array}{l}\text { Airport land } \\
\text { use ( } 1=\text { park, } \\
0=\text { no park })\end{array}$} & \multicolumn{2}{|c|}{$\begin{array}{l}\text { Tram/LRT } \\
(1=\text { stop nearby } \\
0=\text { no stop) }\end{array}$} & \multicolumn{2}{|c|}{$\begin{array}{l}\text { Traffic level } \\
\text { Change }(\%)\end{array}$} & \multicolumn{2}{|c|}{$\begin{array}{l}\text { PTTT to } \\
\text { Athens Centre } \\
\text { (minutes) }\end{array}$} & \multicolumn{2}{|c|}{$\begin{array}{l}\text { Municipal } \\
\text { Tax } \\
\text { (€ per month) }\end{array}$} \\
\hline A & B & $\mathbf{A}$ & B & $\mathbf{A}$ & B & $\mathbf{A}$ & B & $\mathbf{A}$ & B & $\mathbf{A}$ & B \\
\hline 1 & 0 & 1 & 0 & 1 & 0 & 0 & 5 & -5 & 0 & 10 & 0 \\
\hline 1 & 0 & 0 & 0 & 0 & 0 & 0 & 10 & -15 & 0 & 40 & -20 \\
\hline 1 & 0 & 1 & 0 & 1 & 1 & -10 & 8 & 0 & 8 & 25 & -25 \\
\hline 1 & 0 & 1 & 0 & 1 & 0 & -8 & 0 & -10 & 8 & 20 & -15 \\
\hline 1 & 0 & 0 & 0 & 1 & 0 & -15 & 0 & 0 & 10 & 20 & 0 \\
\hline 1 & 0 & 1 & 0 & 0 & 0 & -8 & 0 & 0 & 8 & 20 & 0 \\
\hline 1 & 0 & 0 & 0 & 1 & 1 & -15 & 0 & -10 & 8 & 10 & 0 \\
\hline 1 & 0 & 1 & 0 & 1 & 0 & 0 & 5 & 0 & 10 & 40 & -20 \\
\hline 1 & 0 & 1 & 0 & 1 & 0 & 0 & 10 & -5 & 0 & 25 & -25 \\
\hline 1 & 0 & 0 & 0 & 1 & 0 & -10 & 8 & -15 & 0 & 20 & -15 \\
\hline 1 & 1 & 1 & 0 & 1 & 1 & -10 & 0 & 0 & 10 & 20 & -15 \\
\hline 1 & 1 & 1 & 1 & 1 & 0 & -10 & 10 & 0 & 5 & 20 & 0 \\
\hline 1 & 1 & 1 & 0 & 1 & 0 & -8 & 0 & -15 & 0 & 10 & 0 \\
\hline 1 & 1 & 1 & 0 & 1 & 0 & -15 & 0 & -8 & 0 & 40 & -20 \\
\hline 1 & 1 & 1 & 1 & 0 & 0 & 0 & 5 & -10 & 8 & 25 & -25 \\
\hline 1 & 0 & 1 & 0 & 1 & 0 & 0 & 15 & 0 & 15 & 25 & -25 \\
\hline 1 & 0 & 0 & 0 & 1 & 0 & -5 & 0 & -8 & 0 & 20 & -15 \\
\hline 1 & 0 & 1 & 0 & 1 & 0 & -10 & 0 & -10 & 8 & 20 & 0 \\
\hline 1 & 0 & 1 & 0 & 0 & 0 & -10 & 8 & -10 & 0 & 10 & 0 \\
\hline 1 & 0 & 0 & 0 & 1 & 1 & 0 & 8 & 0 & 5 & 40 & -20 \\
\hline 1 & 1 & 1 & 0 & 1 & 0 & -10 & 8 & -10 & 8 & 40 & -20 \\
\hline 0 & 0 & 0 & 0 & 1 & 0 & 0 & 8 & -10 & 0 & 25 & -25 \\
\hline 1 & 1 & 1 & 0 & 0 & 0 & 0 & 15 & 0 & 5 & 20 & -15 \\
\hline 1 & 1 & 1 & 0 & 1 & 1 & -5 & 0 & 0 & 15 & 20 & 0 \\
\hline 0 & 0 & 0 & 0 & 1 & 0 & -10 & 0 & -8 & 0 & 10 & 0 \\
\hline
\end{tabular}

a The design for OLD6 experiment was slightly modified to avoid presenting scenarios where the respondent is subjected to aircraft noise and at the same time a park is created in the airport land. This modification was possible since the fractional factorial design was in terms of the differences in the attribute levels. This modification was not applied to OLD5 and New airport experimental designs since there is no airport land attribute. 
Table A2: Levels of difference of SC Attributes

\begin{tabular}{|l|l|}
\hline SC Attributes & $\begin{array}{l}\text { Levels of Difference } \\
\text { (Scenario A - Scenario B) }\end{array}$ \\
\hline Aircraft Noise & $0,0,1$ \\
\hline & $0,0,1$ \\
\hline Airport land use & $0,0,1$ \\
\hline Tram/LRT & $-5,-8,-10,-15,-18$ \\
\hline & \\
Road Traffic Level Change (\%) & $-5,-8,-10,-15,-18$ \\
\hline $\begin{array}{l}\text { Public Transport Travel Time to } \\
\text { Athens Centre (minutes) }\end{array}$ & $10,20,35,50,60$ \\
\hline & \\
\hline
\end{tabular}

\section{Appendix B: Survey instructions and sample choice card}

Introduction of the Interviewer to the respondent (Translated from Greek)

(Greeting) We are conducting research, on behalf of the University of Leeds, relevant to the quality of life in your area. We would appreciate if you can spare 15 minutes of your time to answer a brief questionnaire that addresses some important issues of local interest.

Instructions for the Choice Experiment to the interviewee (Translated from Greek)

You will be handed several cards in turn, with each card illustrating two scenarios A and B. These scenarios represent two sets of changes from your current situation in attributes that affect the local quality of life. Please select the one of the two scenarios/sets that you prefer or you find the least detrimental, drawing on past experience. 
Figure B1: Example of a Stated Choice Card from OLD6 Experiment (Translated from Greek)

\begin{tabular}{|c|c|c|}
\hline$M D D$ & SCENARIO A & SCENARIO B \\
\hline $\begin{array}{l}\text { Public Transport Travel } \\
\text { Time to Athens' Centre in } \\
\text { Peak Hours }\end{array}$ & $\begin{array}{l}15 \text { min less than your average } \\
\text { travel time }\end{array}$ & As now \\
\hline Tram & $\begin{array}{l}\text { Tram stop in walking distance } \\
\text { from your house }\end{array}$ & $\begin{array}{l}\text { No Tram stop in walking } \\
\text { distance from your house }\end{array}$ \\
\hline $\begin{array}{l}\text { Area Wide Road Traffic } \\
\text { Level Change }\end{array}$ & As now & 10\% More Traffic \\
\hline Aircraft Noise at Home & $\begin{array}{l}\text { You are not subjected to } \\
\text { Aircraft Noise in your home }\end{array}$ & $\begin{array}{r}\text { You are subjected to Aircraft } \\
\text { Noise in your home (Remember } \\
\text { the situation with the Old } \\
\text { Airport in operation) }\end{array}$ \\
\hline $\begin{array}{l}\text { The Land Use of the Old } \\
\text { Airport }\end{array}$ & $\begin{array}{l}\text { A Park is created in the Airport } \\
\text { land }\end{array}$ & $\begin{array}{l}\text { There is No Park in the Airport } \\
\text { Land }\end{array}$ \\
\hline Municipal Tax & $\begin{array}{l}€ 25 \text { More every month than the } \\
\text { amount you pay now }\end{array}$ & $\begin{array}{r}€ 25 \text { Less every month than the } \\
\text { amount you pay now }\end{array}$ \\
\hline I Choose ... & $\mathbf{A}$ & $\mathbf{B}$ \\
\hline
\end{tabular}

\section{Notes}

${ }^{1}$ The representation of attribute levels for the Tram and LRT variables in the choice scenarios posed an interesting problem. If the respondents were faced with the choice Tram/no-Tram, they were likely to find the No-Tram option improbable. Hence, the choice between a Tram stop within walking distance of one's house and no Tram stop nearby was offered. This was more plausible, since both Tram and LRT networks were still expanding, allowing for the possibility that Tram and LRT stops might change locations.

2 The categorical data from the survey cannot be formally tested against the official data in our disposal. This is because the official income (tax) data are presented as the average income per postcode and do not include any standard error/deviation value.

${ }^{3}$ It is stressed that when the OLD6 experiment was excluded from the models there was no significant impact on the aircraft noise WTP values or on the precision of parameter estimates for the other two experiments.

${ }^{4}$ In the Old Airport experiments the status quo situation is no aircraft noise exposure. Conversely the New Airport respondents were exposed to aircraft noise at the time of the SC survey.

${ }^{5}$ All values in this paragraph are expressed in $€$ that have been adjusted for the purchase parity levels of Greece in 2005. 


\section{References}

Alberola J, Flindell I, Bullmore A (2005) Variability in road traffic noise levels. Applied Acoustics 66: 1180-1195

Arsenio E, Bristow AL, Wardman M (2006) Stated Choice Valuations of Traffic Related Noise. Transportation Research D 11 (1): 15-31

Attenborough K, Clark S (1976) Background noise levels in the United Kingdom. Journal of Sound and Vibration 48(3): $359-375$

Barreiro J, Sanchez M, Viladrich-Grau M (2005) How much are people willing to pay for silence? A contingent valuation study. Applied Economics 37(11): 1233-1246

Baranzini A, Ramirez J V (2005) Paying for Quietness: The Impact of Noise on Geneva Rents. Urban Studies 42(4): 633-646

Bateman I J, Carson R T, Day B, Hanemann M, Hanley N, Hett T, Jones-Lee M, Loomes G, Mourato S, Ozdemiroglu E, Pearce D W, Sudgen R, Swanson J (2002) Economic Valuation with Stated Preference Techniques: A Manual. Edward Elgar Publishing, Cheltenham, UK

Baverstock S J, Pocock R L, Attenborough K (1991) Development of Area-Based Methods for Predicting Ambient Noise. Applied Acoustics 33: 303-312

Bevington P R (1969) Data Reduction and Error Analysis for the Physical Sciences. McGraw-Hill, NewYork.

Bierlaire M (2003) BIOGEME: A free package for the estimation of discrete choice models. Proceedings of the 3rd Swiss Transportation Research Conference, Ascona, Switzerland

Bierlaire M (2008) Estimation of discrete choice models with BIOGEME 1.8. Available via:

www.biogeme.ep.ch. Cited 11 May 2009

Bjørner T B (2004) Combining socio-acoustic and contingent valuation surveys to value noise reduction. Transportation Research D 9: 341-356

Bristow A L (2010) Valuing Noise Nuisance. Paper presented at the 39th International Congress and Exposition on Noise Control Engineering, Lisbon, 13-16 June 2010 
Bristow A L, Arsenio E, Wardman M (2009) Influences on the value of noise from transport. Paper presented at the 8th European Conference on Noise Control, Edinburgh, 26-28 October 2009

Bristow A L, Wardman M (2006a) Valuation of Aircraft Noise by Time of Day: A Comparison of Two Approaches. Transport Reviews 26 (4): 417-433

Bristow A L, Wardman M (2006b) What influences the value of aircraft noise? Paper presented at the European Transport Conference AET, Strasbourg, 18-20 September 2006

Carlsson F, Lampi E, Martinsson P (2004) Measuring marginal values of noise disturbance from air traffic: Does the time of the day matter? Transportation Research D 9: 373 - 385

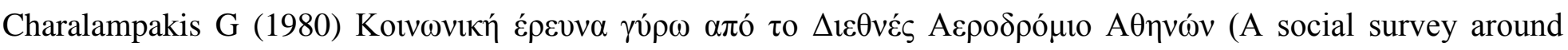

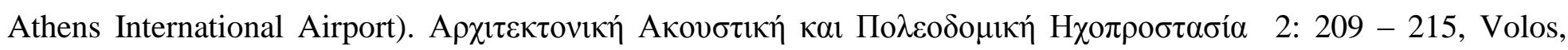
Greece

Dave K, Toner J, Chen H (2009) Examining the Effect of Attribute Representation on Preference Uncertainty. Paper presented at the Choice Modelling International Conference, Harrogate, 30-32 March 2009

Day B, Bateman I J, Lake I (2007) Beyond implicit prices: recovering theoretically consistent and transferable values for noise avoidance from a hedonic property price model. Environmental and Resource Economics 37(1): 211-232

Duarte C M, Cladera J R (2008) The noise impact on residential environments in contemporary metropolises: the case of Barcelona. XII Conference of the Institute of Urban Design: "The Heart of the City", Krakow, Poland European Environment Agency (2010) Towards a resource-efficient transport system. TERM 2009: Indicators tracking transport and environment in the European Union. EEA Report No2/2010.

European Council EC (2002) Directive 2002/30/EC on the establishment of rules and procedures with regard to the introduction of noise-related operating restrictions at Community airports. Official Journal of the European Communities L 85/40

Faburel G (2001) Le bruit des avions - Evaluation du coût social. Presses Ponts et Chaussées (in French), University of Paris 12, France 
Federal Aviation Administration (2003) Integrated Noise Model. FAA, U.S. Department of Transportation, Washington, USA.

http://www.faa.gov/about/office_org/headquarters_offices/aep/models/inm_model/ . Cited 15 August 2010

Feitelson E, Hurd R, Mudge R (1996) The impact of airport noise on willingness to pay for residences. Transportation Research D 1: 1-14.

Garrod G D, Scarpa R, Willis K G (2002) Estimating benefits of traffic calming on through routes: a choice experiment approach. Journal of Transport Economics and Policy 36: 211-231

Garcia A, Faus L J, Garcia A M (1993) The community response to aircraft noise around six Spanish airports. Journal of Sound and Vibration 174 (1): $45-52$

Galilea P, Ortuzar J de D (2005) Valuing noise level reductions in a residential location context. Transportation Research Part D 10: 305-322

Hanley N, Mourato S, Wright R E (2001) Choice modeling approaches: a superior alternative for environmental valuation? Journal of Economic Surveys 15: 435-462

Hensher D A, Greene W H (2003) The Mixed Logit Model: The State of Practice. Transportation 30 (2): 133-176 Hensher D A, Rose J M, Greene W H (2005) Applied Choice Analysis. A primer. Cambridge University Press, New York.

Hess S (2008) Treatment of reference alternatives in stated choice surveys for air travel choice behaviour. Journal of Air Transport Management 14 (5): 275-279

Hole A R (2007) A comparison of approaches to estimating confidence intervals for willingness to pay measures. Health Economics 16 (8): 827-840

Hökby S, Söderqvist T (2003) Elasticities of demand and willingness to pay for environmental services in Sweden. Environmental and Resource Economics 26 (3): 361-383

Horowitz JK, McConnell K.E (2002) A review of WTA/WTP studies. Journal of Environmental Economics and Management 44: 426-447 
Hoyos D (2010) The state of the art of environmental valuation with discrete choice experiments. Ecological Economics 69: 1595-1603

Jacobsen J B, Hanley N (2009) Are there income effects on global willingness to pay for biodiversity conservation? Environmental and Resource Economics 43(2): 137-160

Kristrom B, Riera P (1996) Is the Income Elasticity of Environmental Improvements Less Than One? Environmental and Resource Economics 7: 45-55

Le Masurier P, Taylor J, Roberts M, Pownell C, Flindell I, Bates J (2008) A national study of attitudes to aircraft noise and willingness to pay. Paper presented at the European Transport Conference (ETC), Leiden, Netherlands, 6-8 October 2008

Louviere J J, Hensher D A, Swait J D (2000) Stated Choice Methods Analysis and Applications. Cambridge University Press, Cambridge UK

Miedema H M E, Vos H (1999) Demographic and attitudinal factors that modify annoyance from transportation noise. Journal of the Acoustical Society of America 105 (6): 3336-3344

Murphy J J, Allen P G, Stevens T H, Weatherhead D (2005) A Meta-Analysis of Hypothetical Bias in Stated Preference Valuation. Environmental and Resource Economics 30: 313-325

National Statistical Service of Greece (2005) Statistical Data for Greece (in Greek). General Secretariat of National Statistical Service of Greece, Ministry of Economy and Finance, Piraeus, Greece. Available via: http://www.statistics.gr/Cited 19 April 2008

MVA (2007) Attitudes to Noise from Aviation Sources in England. Final Report for the Department for Transport (DfT), Norwich, UK

http://webarchive.nationalarchives.gov.uk/+/http://www.dft.gov.uk/pgr/aviation/environmentalissues/Anase/ . Cited 17 August 2010

Nelson J P (2004) Meta-analysis of Airport Noise and Hedonic Property Values: Problems and Prospects. Journal of Transport Economics and Policy 38(1) pp1-28 
Nellthorp J, Bristow A L, Day B (2007) Introducing willingness-to-pay for noise changes into transport appraisal an application of benefit transfer. Transport Reviews 27(3): 327-353.

Nicol F, Wilson M (2004) The effect of street dimensions and traffic density on the noise level and natural ventilation potential in urban canyons. Energy and Buildings 36: 423-434

Pearce D W (1980) The social incidence of environmental costs and benefits. In: O'Riordan T, Turner R K (Ed) Progress in Resource Management and Environmental Planning. John Wiley and Sons, Chichester, p 66

Pommerehne W W (1988) Measuring Environmental Benefits: A Comparison of Hedonic Technique and Contingent Valuation. In: Bos D, Rose DM, Seidl C (Ed) Welfare and Efficiency in Public Economics. Springer-Verlag, Berlin, p 363

Sælinsminde K (1999) Stated choice valuation of urban traffic air pollution and noise. Transportation Research D 4 (1): $13-27$

Thanos S (2008) Valuation of Aircraft Noise Annoyance: A Comparison of Approaches in the Context of Airport Relocation. PhD thesis, Institute for Transport Studies, University of Leeds.

Thune-Larsen H (1995) Flystøyavgifter basert på betalingsvillighet, TOI report 289/1995, Institute for Transport Economics, Oslo (English language summary report: Charges on Air Traffic Noise by Means of Conjoint Analysis) Vainio M (2001) Comparison of hedonic prices and contingent valuation methods in an urban traffic noise context. Paper presented at the International Congress and Exhibition on Noise Control Engineering 2001, Hague Wardman M (2001) Intertemporal variations in the value of time. Working Paper 566, Institute for Transport Studies, University of Leeds

Wardman M, Bristow A L (2004) Traffic Related Noise and Air Quality Valuations: Evidence from stated preference residential choice models. Transportation Research D 9: 1- 27

Wardman M, Bristow A L (2008) Valuations of aircraft noise: experiments in stated preference. Environmental and Resource Economics 39(4): 459-480

Yang W, Kang J (2005) Acoustic comfort evaluation in urban open public spaces. Applied Acoustics 66: 211-229 